\title{
A INSTRUÇÃO PÚBLICA BRASILEIRA NOS PANFLETOS DE TAVARES BASTOS (1861-1873)
}

\author{
Josefa Eliana Souza \\ Universidade Federal de Sergipe - UFS
}

\section{RESUMO:}

Neste estudo, a finalidade é compreender o modo como Tavares Bastos tratou a instrução pública brasileira, na década de 60 e início de 70 do século XIX, no que denominou de "programa de instrução pública brasileira". Foram examinados os panfletos que o autor/parlamentar publicou entre os anos de 1861 a 1873. A análise dessa produção permite identificar elementos que constituem o "programa de instrução pública" almejado por Tavares Bastos e afirmar que elementos de modelos norte-americanos foram mobilizados, sobretudo o implementado por Horace Mann e os apresentados por Aléxis Tocqueville, como um amálgama adequado para conduzir o povo brasileiro ao caminho do progresso e da civilização. Ao pinçar elementos que constituem esses modelos, Tavares Bastos produziu os argumentos para defender a escola gratuita e universal, o ensino obrigatório, escola mista, programa de ensino voltado, sobretudo, para o conhecimento baseado em princípios práticos e que possibilitassem ao aluno um tipo de formação mais adequada às necessidades do trabalhador da indústria, do comércio e da agricultura da época.

Palavras-chave: Tavares Bastos. Instrução pública brasileira. Modelo educacional norteamericano. Horace Mann. Aléxis de Tocqueville.

\section{BRAZILIAN PUBLIC EDUCATION AS PRESENTED IN TAVARES BASTOS'S PAMPHLETS (1861-1873)}

\begin{abstract}
:
The objective of this study is to understand the way Tavares Bastos dealt with Brazilian public education in the 60's and in the beginning of the 70's, in the XIX century, as for what he named "the Brazilian public education program". Such task, pamphlets the author/politician published between the years of 1861 and 1873 were examined. The analysis of such work allows identifying elements that are part of the "program of public education" aimed at by Tavares Bastos, and it emphasis that elements of the NorthAmerican models were used, mainly the one implemented by Horace Mann, and the ones presented by Aléxis Tocqueville, as an appropriate amalgam to direct the Brazilian people towards the path of progress and civilization. By picking elements that constitute those models, Tavares Bastos built arguments in order to defend the idea of a free and universal school, mandatory education, co-education schools, and a teaching program dedicated mainly to knowledge based on practical principles that would provide the students with a kind of training that would be more adequate to the needs of workers from the fields of industry, commerce, and agriculture of that time.

Keywords: Tavares Bastos. Brazilian public education. North-American educational model. Horace Mann. Aléxis de Tocqueville.
\end{abstract}


Os escritos produzidos por Tavares Bastos têm sido tomados, desde a década de 70 do século XX, como fonte para estudos que investigam temas associados a aspectos políticos, econômicos e sociais que dizem respeito aos anos 60 e início de 70 do século XIX. Livre cambismo, defesa da abertura do Rio Amazonas e navegação de cabotagem, descentralização, incentivo à vinda de emigrantes para o Brasil e as reformas educacional, financeira, eleitoral e da magistratura, são alguns do temas examinados a partir da produção desse parlamentar. Neste estudo, examina-se o destaque dado por Tavares Bastos para propor a reorganização escolar brasileira, na segunda metade do século XIX, recorrendo principalmente a modelos norte-americanos. Deve-se ressaltar que, desde o exame preliminar da produção desse autor, é possível constatar a não elaboração por ele de um texto com foco de análise e reflexão apenas sobre a educação/instrução. E, ao que tudo indica, esse é um aspecto da singularidade da produção de Tavares que será examinada como parte de um conjunto de escritos produzido entre 1861 e 1873.

Deste modo, foram localizadas e reunidas as fontes e, para o estudo delas, partiu-se do princípio de que a história da educação tem as suas especificidades no que tange à leitura e à compreensão dos documentos a serem verificados. Por isso que, nesta pesquisa, coube o exame dos panfletos produzidos por Tavares Bastos, entre os anos de 1861 a 1873, no que se refere à discussão voltada para instrução pública.

Assim, o exame dos Annual Reports, ou seja, o estudo dos relatórios produzidos anualmente por Horace Mann, em Massachusetts (EUA), são importantes para a discussão acerca da contribuição norte-americana nos escritos de Tavares Bastos, posto que o deputado brasileiro afirma seu interesse pelos relatórios publicados por Horace Mann, além da presença de temas e soluções inspiradas no estudioso norte-americano. Assim, cabe destacar também, a contribuição da obra A Democracia na América na construção das idéias apresentadas por Tavares Bastos, sobretudo, no que diz respeito à escola como um ambiente indispensável para a formação da unidade e identidade nacional e na discussão que trata da educação como uma forma de integrar o imigrante à sociedade brasileira, uma vez que, os referidos temas suscitaram a atenção do pesquisador francês, no estudo que realizou sobre a sociedade norte-americana.

\section{Males da Educação}

Não esqueçamos a educação pública, mãe do progresso. Pois bem! temos observado nisso o sistema pior. A nulidade da instrução elementar; o ensino do pernicioso latim como de um instrumento de civilização; a falta de difusão das ciências naturais e conhecimentos úteis; a existência de professores, ou totalmente inábeis, ou principiantes ainda; a ausência de rigor nos exames dos cursos superiores; a conseqüente abundância de médicos e bacharéis, outros tantos solicitadores de emprego, outros tantos braços perdidos para o trabalho livre e para a empresa individual, eis, sem dúvida, uma cadeia de causas bastante fortes para comprometer seriamente o futuro de um país qualquer (TAVARES BASTOS, 1976a, p. 37).

Esse quadro traçado por Tavares Bastos em Os males do presente e as esperanças do futuro é representativo da situação em que se encontrava, à época, a educação no Brasil, e que passou a ser foco freqüente de interesse desse parlamentar, quando começou a lançar 
as prescrições para realizar as reformas que promoveriam a modernização do país. Uma das primeiras críticas por ser considerada como causa do atraso brasileiro, é indicada, pelo autor, como sendo originada na colonização e dominação portuguesa. $\mathrm{O}$ autor refere-se à devastação promovida por Portugal no âmbito da política e da economia desenvolvida no Brasil.

Assim, a colônia havia herdado os "males" de uma metrópole arcaica e pouco produtiva, pois, presa que sempre estivera aos efeitos da burocracia improdutiva, não tivera condições de avançar tanto quanto outras nações modernas. Por isso, se o Brasil tinha necessidade de por em prática o conjunto das transformações que lhe cabia, era fundamental olhar noutra direção para processar as mudanças e criar uma nação livre da ignorância e pronta a ascender à condição de civilizada.

No conjunto dos males que impediam o acesso do país ao crescimento e processo civilizatório, aparecia o do atraso no âmbito da educação. Chamava atenção para o "desenvolvimento moral" de povos de outras nações. Apesar de reconhecer que algum progresso poderia ser verificado no Brasil, era indispensável a difusão da "instrução elementar e dos conhecimentos úteis" tanto para o habitante da cidade quanto para o do interior. Estas condições, segundo Tavares Bastos (1938, p.65) seriam como alimento para o espírito da gente brasileira.

Tavares Bastos estava ciente do pequeno número de escolas públicas brasileiras distribuídas entre os níveis elementar, secundário e superior, da má formação do professorado, das péssimas condições para a manutenção material da escola pública, da baixa remuneração dos professores e do baixo rendimento do aluno, como dados que não poderiam ser esquecidos ou minimizados, sob pena de perder a dimensão dos problemas que afligiam a educação pública em qualquer província do império no século XIX.

Entretanto, outro problema se somava aos já existentes e dizia respeito à forma como estava estruturada a organização político-institucional reinante no país. Nesse sentido, Tavares Bastos criticava a ausência de liberdade no funcionamento das províncias em relação ao governo central. Esse fato foi observado por Justiniano José da Rocha e citado por Tavares Bastos, como se percebe nas críticas irônicas do panfletário: "ao governo se dirigem todos os votos, todas as aspirações a melhoramentos; o governo é por todos invocado, até quando se quer, para divertimento da Capital, contratar cantoras e bailarinas!" (ROCHA apud TAVARES BASTOS, 1976a, p.45).

Preocupado com tais circunstâncias, Tavares Bastos (1976a) procurou fazer a crítica do funcionamento da referida estrutura e apontou para os problemas dela advindos. As queixas, contra a forma como funcionavam as diversas instâncias que administravam o país, apontavam para o distanciamento entre o governo central e as administrações das províncias do Brasil. O processo promovia embaraços que se somavam aos da distância territorial e da distância entre as populações e os governantes. A demora e a dependência de decisões por parte das autoridades locais contribuíam para que a autoridade ficasse à espera de uma resposta proveniente de outra autoridade pertencente à outra instância. Assim, uma decisão da província dependia de uma resposta que deveria partir do governo central.

Essa estrutura, a partir da avaliação de Tavares Bastos, afetava a administração das províncias, promovendo conseqüências que atingiam diretamente diversos setores da vida pública. Segundo o parlamentar alagoano, a falta de respeito à iniciativa das chefias e a responsabilidade que cabia, segundo a lei, a cada um dos trabalhadores, fazia com que o sistema administrativo fosse uma máquina emperrada que atrasava todo o funcionamento das províncias. 
Na prática, para ele, as mais elementares leis da economia eram desrespeitadas por conta do desperdício de tempo, ocupação exagerada de pessoal e muitas interrupções no aguardo de uma ordem superior que ignorava a iniciativa e a responsabilidade que, segundo Tavares Bastos, era própria de cada trabalhador.

O atraso da máquina burocrática atrapalhava também o funcionamento da educação pública, que ficava presa a outro tipo de centralização política. Apesar da descentralização promovida pelo Ato Adicional de 1834 no campo educacional, ainda assim, a escola pública ficava a mercê de medidas e decisões tomadas pelo governo central. Segundo Tavares Bastos (1938), a idéia da centralização do ensino superior na Corte não iria contribuir para reduzir a ignorância ou a depravação dos costumes.

Segundo o autor, a forma como o governo central conduzia as medidas e decisões, no âmbito da educação pública, eram marcadas pelos hábitos que haviam sido herdados da indolência e da aparência e comprometiam o funcionamento do ensino público nas províncias. Contudo, segundo Tavares Bastos (1938), nenhuma medida efetiva havia sido tomada pelo governo para conter esses problemas. O governo brasileiro apenas continuava dedicando-se às medidas formais, que mais atrapalhavam do que ajudavam.

\section{Um modelo de progresso de civilização}

Tavares Bastos (1976a) havia percebido desde a publicação de Os males do presente e as esperanças do futuro que as mudanças operadas nos Estados Unidos da América eram significativas e que era preciso ver com maior atenção a dimensão daqueles fatos. Entendia o autor/parlamentar que, naquele país, estavam acontecendo mudanças que deveriam ser vistas e analisadas pelos representantes do povo. Sabia que a Europa, para muitos deles, continuava sendo o lugar para onde as atenções continuavam a ser direcionadas. Contudo, afinado com o que de novo acontecia no mundo ocidental, não tinha dúvidas, e apesar, das oposições, insistiu, nos diversos artigos e panfletos que publicou, estar o "novo" se realizando no norte do continente americano. Aquela civilização constituída a partir dos valores ingleses havia conseguido superar a metrópole. Nesse mesmo sentido, carecia que, no Brasil, a sociedade se libertasse dos valores ultrapassados e constituísse uma nação pautada nos valores do progresso e da civilização.

Entende-se que o autor considera que a transformação é possível. Mas, ela só ocorreria se os hábitos da sociedade inteira fossem mudados. Essa mudança deveria se processar nos diversos setores da sociedade brasileira. O contato entre os dois povos poderia modificar os costumes e hábitos degenerados da população do Brasil. Por isso, fazia-se necessário estreitar, cada vez mais, as relações entre os brasileiros e os norteamericanos.

A esperança na transformação é assim evidenciada por Tavares Bastos ao publicar o segundo panfleto em 1862, no qual já explicitava com maior clareza que no do ano anterior, as idéias acerca do que deveria ser realizado no país, chamando atenção dos pares para o monopólio da navegação de cabotagem, insistindo na contribuição moral, social e política, das facilidades do trânsito, lembrando ainda que, nos Estados Unidos, vivia-se a descentralização administrativa e política e cada membro da unidade encontrava-se perfeitamente unido e no mais estreito contato, não obstante a independência de cada um dos membros da república. Dessa forma, os norte-americanos tinham conseguido sua unidade e facilitado as comunicações internas. Esse fato trazia conseqüências pedagógicas, pois contribuía para amalgamar culturas diferençadas dos povos que constituíram aquela sociedade (TAVARES BASTOS,1938, p. 35). 
A riqueza propiciada na constituição da sociedade norte-americana deveria ser analisada com muita atenção pelos governantes brasileiros. Assim, Tavares Bastos conclamava os seus pares para observar que, no Brasil, havia problemas resultantes da nossa colonização e que era preciso extirpá-los. Para isso, chamava atenção dos que o consideravam pouco patriota por alimentar a idéia da proximidade entre o Brasil e os Estados Unidos da América. Consciente das críticas das quais era motivo e como meio de expressar a sua posição perante os seus opositores, afirmava: "Eu não exagero as tendências da minha natureza americana" (TAVARES BASTOS, 1938, p. 247).

Era a prosperidade, o crescimento moral e intelectual aliado à fé inabalável da energia e audácia que, segundo o parlamentar, tinham os norte-americanos, que conduziam o olhar de Tavares Bastos (1938). Segundo o autor, não existia um modelo mais apropriado do que o daquela sociedade para servir de referente ao povo brasileiro. Nesse sentido, acreditava que era conveniente despir-se das heranças da colonização portuguesa e aproximar-se, cada vez mais, solicitando os auxílios e partilhando os resultados oriundos daquele modo de viver e sentir.

Em que pese existirem, nos textos de Tavares Bastos (1938), as marcas do caldo de cultura européia, é inegável o destaque que foi concedido pelo autor para a contribuição norte-americana. Ao que tudo indica, à sua época, o autor almejava o que posteriormente foi identificado por Warde (2001) como um processo de conformação, que iria constituirse num mecanismo que plantaria nos corações e mentes a semente de um homem moderno e, nesse sentido, moldaria "formas de pensar, sentir e viver; tornando-se parâmetro de progresso, felicidade, bem estar, democracia, civilização; moldando as esperanças em torno da cidade e da indústria. Redimensionando espaços e acelerando os tempos" (WARDE, 2001, p.13).

Tavares Bastos tinha clareza acerca do que afirmava, em que pese tenha encontrado oposições. Porém, amparado na idéia de que a sociedade brasileira carecia de novos princípios para fazer com que o país fosse revigorado pelos benefícios de outros valores, que buscasse o caminho da superação e a crença de que era possível alterar, com profundidade, o quadro de atraso e de ignorância que só servia para limitar os poderes de uma sociedade que, no futuro, poderia vir a ser uma das mais importantes e civilizadas do mundo.

Causa curiosidade saber: de onde se originou o interesse do autor/parlamentar pela reforma educacional realizada em Massachusetts e pelo crescimento e progresso dos Estados Unidos da América? A partir de uma investigação da trajetória acadêmica de Tavares Bastos, é possível afirmar que o contato com o professor José Tell Ferrão foi importante, no sentido de aproximá-lo da cultura norte-americana.

Foi no ambiente da Faculdade de Direito de São Paulo que Tavares Bastos conheceu Tell Ferrão e, posteriormente, na publicação lançada em 1862, em uma das "Cartas do Solitário", ao explicar a relevância do estreitamento das comunicações entre o Brasil e os Estados Unidos da América, dizia que isto serviria à "reforma moral do país e ao progresso". Nesse texto, rendia homenagens a quem havia lhe ensinado a "olhar" para os Estados Unidos da América:

[...]Dr. José Tell Ferrão, professor na faculdade de São Paulo entre os anos de 1856 e 60, que nunca cessava de comunicar aos íntimos o seu profundo entusiasmo pelos Estados Unidos, aonde fizera a sua educação literária. Ninguém estranhará esta homenagem rendida, ainda que tarde, perante os nossos amigos, ao nome simpático e venerado do Dr. Ferrão (TAVARES BASTOS, 1938, p. 415). 
Tavares Bastos foi convidado pelo professor Tell Ferrão para prefaciar o livro do ex-mestre da Faculdade de Direito de São Paulo. Essa experiência foi benéfica para Tavares Bastos, tanto porque despertou no ex-aluno o interesse pelas questões diretamente ligadas à educação brasileira e também porque o levou a entrar em contato com informações sobre os Estados Unidos.Contudo, o interesse de Tavares Bastos pelos Estados Unidos encontraria outra razão para aprofundá-la e esta foi James Cooley Fletcher (1823 -1901).

Após vinte anos de esforços vãos para preencher o cargo de capelão do porto do Rio de Janeiro, a sociedade dos marítimos americanos enviou ao Brasil esse ministro presbiteriano, que havia se oferecido para a missão de servir os americanos aqui residentes. Fletcher estaria, juntamente com Tavares Bastos, na propaganda de defesa da imigração, tendo até mesmo participado da Sociedade Internacional de Imigração, da defesa da abertura do rio Amazonas para o comércio internacional, além de ser um divulgador da reforma educacional realizada por Horace Mann, em Massachusetts, entre os anos de 18371848. Segundo Vieira (1980, p.74), a missão de Fletcher era protestantizar o Brasil sob o ponto de vista religioso, social, econômico e cultural. E por isso, Fletcher se encarregou de apresentar os EUA como o lugar do progresso e que o Brasil teria condição de alcançá-lo. Para que o progresso se realizasse era importante, entre outros aspectos, o cuidado com a educação. Esta era "representada pelo sistema de escola pública preconizado por Horace Mann. O modelo Horace Mann foi propagado por Fletcher no Brasil" (Vieira, 1980, p, 74). Essas idéias uniram Fletcher e o parlamentar alagoano.

\section{A contribuição de horace Mann e da organização do ensino público em Massachusetts}

Tavares Bastos ao escrever A Província registra indicativo de que esse parlamentar apreciava o sucesso do empreendimento realizado por Horace Mann, em Massachusetts. $\mathrm{O}$ êxito dessa reforma projetou o nome do seu autor para fora do ambiente norte-americano, frequentemente sendo tratado como The Father of the Common School (cf. Buck, 2002, Grant 2005, Weiler 2003, Spring 1996) ${ }^{1}$. Será que, de algum modo, Tavares Bastos também procurou imitar ou adotar aspectos dessa reforma no Brasil? Para que se busque resposta para essa indagação, necessário se faz examinar alguns elementos dessa reforma, na tentativa de compreender se e de que maneira Tavares Bastos procurou incorporá-los ao programa de reforma da instrução que intentava para o Brasil da época.

Por conta desse fato, optou-se pela realização de um exame dos Anuual Reports, produzidos anualmente por Horace $\mathrm{Mann}^{2}$, pois esse foi um dos dispositivos utilizados por ele para apresentar o conjunto dos elementos que deveriam compor a educação em uma sociedade livre ${ }^{3}$. Alguns dos elementos considerados fundamentais para implantação e implementação da common school da reforma idealizada por Horace Mann estão apresentado nos Reports.

Eles podem ser sumarizados da seguinte forma: em 1837 foi lançado o primeiro relatório e versa sobre quatro necessidades essenciais das escolas públicas - bons prédios, conselhos escolares locais inteligentes, empenho público generalizado a favor da educação universal, e professores competentes. O segundo foi lançado em 1838 e traz questões relacionadas à leitura, soletração e composição nas escolas e apresenta recomendações sobre o tema. O terceiro relatório trata especialmente, da necessidade de bibliotecas públicas gratuitas, como um complemento para a escola pública. Sugere a organização de bibliotecas circulantes gratuitas em cada distrito escolar do Estado. Temas diversos compuseram o relatório publicado em 1840, a exemplo de edifícios escolares, necessidade de consolidar os distritos escolares excessivamente pequenos, escolas particulares, 
problemas de frequiência e de disciplina. Apresenta uma discussão sobre as aptidões dos professores. Horace Mann publicou em 1841, o quinto relatório e tratou de abordar nesse também os edifícios para escolas, aptidões dos professores e ameaça de dissensões religiosas nas escolas. Mas, o tema principal é a habilidade de vender e no sexto relatório, o autor defendeu a educação física e sanitária.

Os relatórios de Horace Mann continuaram sendo publicados. Em 1843, ele apresentou comentários e observações sobre a viagem de inspeção que realizou as escolas da Inglaterra, Irlanda, Escócia, Alemanha, Holanda, Bélgica e França. Contudo, o documento que publicou em 1844 não teve um tema central e nele foram abordados múltiplos problemas do sistema de escola pública, em crescimento além, de apresentar discussões resumidas sobre as escolas particulares, verbas para os estabelecimentos de ensino, questões vinculadas à disciplina, admissão de professores e efeitos benéficos dos institutos de professores. No relatório publicado em 1845, foi discutida a posição social; a educação dos professores e os progressos mais gerais das escolas de Massachusetts. $\mathrm{O}$ tema principal do referido documento foi a primazia da educação moral sobre a intelectual. No décimo relatório há um discurso geral sobre as escolas de Massachusetts e em exposição pormenorizada do código de educação estadual. No décimo primeiro relatório está a discussão sobre o poder da educação universal, no sentido de redimir o Estado de qualquer maneira de vício ou de crime social. E no último relatório, publicado em 1848, está um resumo das idéias de Mann sobre educação. Nesse relatório ele reuniu temas dos primeiros relatórios em um único "grande credo da educação pública".

Observa-se, pelo que afirma Mann (1963) em seus relatórios, que, por meio da legislação local, se procurava regulamentar aspectos que por certo garantiria o bom funcionamento, eficiência e utilidade do sistema escolar. Por exemplo, a legislação de Massachusetts estabelecia, para cada cidade que possuísse população numerosa e com riqueza suficiente, fosse criada uma escola de "caráter mais adiantado". Esta deveria receber as crianças, independente da classe, especialmente os filhos dos pobres que não pudessem arcar com as despesas para que os filhos pudessem estudar fora do seu domicílio.

Parece que, com critérios desse tipo, Mann (1963) esperava que a escola pudesse fornecer a preparação indispensável para a formação do aluno, tanto sob o aspecto da moralidade quanto da segurança.

Ao discutir a questão do ensino público, Mann (1963) considerou que era necessário construir uma escola que levasse em conta a relação integral entre a liberdade, a educação popular e o governo republicano. Sabia que uma nação não podia ficar livre por muito tempo, tendo uma população ignorante. Mesmo que o país detivesse uma estrutura política conveniente, não seria capaz de manter os direitos e as liberdades dos cidadãos. Essas idéias estavam afinadas com o que acontecia naquele momento, no país.

Nos Estados Unidos, do século XIX, o crescimento do comércio e da indústria passou a exigir empregados que dominassem a técnica do ler, escrever e calcular necessários tanto em escritórios quanto nas fábricas. E essa passou a ser uma preocupação tanto dos homens de negócios quanto dos reformadores. Além disso, passou a ser preocupação de todos a possibilidade de que as grandes diferenças sociais, resultantes do desenvolvimento econômico, pudessem causar transtornos sociais e aumentar a desigualdade social.

Os reformistas passaram a empreender esforços para superação dessa situação e passaram a defender que a igualdade e a igualdade de oportunidade eram necessárias ao republicanismo americano, percebendo que era fundamental criar oportunidades para que a República se mantivesse. E um caminho para isso era a educação universal, que 
favoreceria tal oportunidade. Uma das bandeiras de luta passou a ser que a verdadeira igualdade de oportunidades só seria atingida se a educação fosse propiciada a todos na mesma escola, com os mesmos livros, cursos e inclusive alimentos e roupas.

Diante desse quadro, Mann (1963) passou a defender que cabia garantir a liberdade a partir da ampla distribuição do conhecimento para toda a população. Por isso, lutava por uma educação popular e universal como o fundamento que deveria nortear as ações governamentais como base para a própria segurança.

Ao fazer essa análise, Mann (1963) inferiu acerca da necessidade de aprofundar a questão, pois o fundamental era favorecer a elevação moral do povo. $\mathrm{O}$ conhecimento era a chave para o bem e para o mal. Por isso, era preciso ver adiante e saber que a educação republicana não se faria somente pelo conhecimento intelectual, mas pelos valores que deveriam ser adensados como o autogoverno, o autocontrole, a submissão voluntária às leis da razão e do dever. Essas características seriam garantidas por meio da implantação de uma nova proposta de organização curricular.

Mann (1963) destacou-se por orientar que a common school teria a função de dedicar-se à "educação geral" e, se o aluno fosse direcionado, nesse momento, para alguma atividade profissionalizante específica, fugiria ao objetivo que propunha, a educação geral. Nesse sentido, Mann (1963) defendeu, por exemplo, o ensino da música vocal: sensibilidade estética, saúde física, exercício intelectual e influências morais. Segundo Mann (1963), no âmbito da sensibilidade estética, a prática da música vocal seria importante para a saúde, porque aumentaria a ação dos pulmões, estimulando a circulação e propiciando a purificação do sangue. Outro benefício seria também possibilitar uma maior rapidez no processo digestivo. No que diz respeito ao exercício intelectual, destacava a relação com a matemática, pois os tons musicais apresentam uma relação direta com esse campo do conhecimento.

Mas, para esse autor, os benefícios da música excederiam qualquer estímulo proporcionado aos aspectos da saúde física ou da intelectualidade, pois, se comparados ao aspecto moral, superaria em muito outros aspectos, por ser útil para conter as paixões dos jovens, além de intensificar a disciplina nas salas de aula e funcionar como um grande tranqüilizador juvenil.

No último relatório, fase em que já desempenhava o cargo de Senador no Congresso dos Estados Unidos, Mann (1963, p.97) reúne os temas que constituíam o "grande credo de educação pública". Nesse texto, explica que os meios usados pela educação norte-americana formavam a máquina por meio da qual a matéria-prima "da natureza humana se transforma em inventores e descobridores, hábeis artífices e fazendeiros científicos, sábios e juristas, fundadores de instituições de beneficência e grandes expositores da ciência moral e teológica" (MANN, 1963, p. 97). Essa formação prepararia o norte-americano para o exercício das funções que o mercado exigisse.

Observa-se que, reiteradas vezes, o autor defendia que a educação iniciasse na fase mais tenra da vida humana, e propiciasse situações para que os talentos se desenvolvessem e, posteriormente, fossem capazes de resolver problemas em variados setores das atividades humanas. Desse modo, entendia que a common school aperfeiçoada se tornaria na mais "eficaz e mais benigna de todas as forças da civilização" (MANN, 1963, p. 98). E, por sua universalidade de atuação, que não era perceptível, nenhuma outra instituição, sobre a forma como atuava, poderia contribuir de forma diversificada para o surgimento de variadas possibilidades de atuação.

Segundo Mann (1963, p. 98), um exemplo dos bons resultados alcançados pelas common school, no Estado de Massachusetts, poderia ser exemplificado pelo "o ensino de cegos, mudos e surdos, na maneira de despertar a centelha da inteligência que se esconde 
no espírito do idiota, e na obra mais sagrada de reformar crianças abandonadas e desprezadas, a educação mostrou o que pode fazer, mediante gloriosas experiências".

Ainda segundo esse autor, as transformações desenvolvidas na infância, a despeito do limite do conhecimento, quando desenvolvidas certas faculdades, preparariam o ser humano para manejar poderosas armas para proteger a sociedade contra toda sorte de problemas que pudessem surgir na fase adulta. A defesa do autor, como já explicitada anteriormente, era que o preparo adquirido na sala de aula se expandisse para as demais instituições e para o desenvolvimento do Estado.

Constata-se, também, que os dirigentes da common school, defendida por Mann (1963), estavam preocupados em afastar o desconforto que representava moléstia crônica ou debilidade, em qualquer membro da família. O reformista entendia que a falta de saúde e de resistência representa perda para a comunidade, por isso cada cidadão deveria olhar os seus concidadãos não só com a benevolência cristã, mas também, como um homem de negócio.

Segundo Mann (1963), o conhecimento científico era para ser utilizados nas várias atividades do fazer humano. Pois, se a ciência provou que a saúde depende da sua conduta, cabia instruir a criança e proporcionar preparo para a preservação da saúde durante todo o curso escolar, que incutisse na criança as poderosas forças do hábito da obediência. Além de introduzir a fisiologia humana como um ramo de estudo nas escolas públicas, caberia desenvolver a temperança e a moderação, ao lado da observância religiosa de todas as regulações sanitárias. Desse modo, seria formada uma raça "de homens e mulheres de estatura mais nobre, de estrutura mais firme, de forma de maior beleza, mais capazes de cumprir com os deveres da vida e suporta-lhe as responsabilidades" (MANN, 1963, p. 102103).

Assim, além dos cuidados com a preparação física do ser humano, os responsáveis pela common school deveriam também cuidar da educação intelectual como um meio de acabar com a pobreza e promover o acesso a melhores condições de vida intelectual e econômica. Nesse sentido é que Mann (1963) efetua a crítica à sociedade européia, ao dizer que lá os homens dividiam-se em classes e de acordo com a divisão - uns deveriam trabalhar e ganhar daquilo que produziu e outros eram para tomar conta e fruir. Portanto, os Estados europeus estavam de olhos fechados para o princípio da oportunidade

De acordo com a teoria do Massachusetts, todos devem ter a mesma oportunidade para ganhar a segurança igual para o gozo do que ganham. Esta última tende à igualdade de condição; a primeiras desigualdades mais grosseiras. Examinadas segundo padrões de moral cristã, ou mesmo conforme os padrões pagãos da melhor sorte, poderá alguém hesitar, por um momento sequer, em declarar qual dos dois produzirá o maior volume de bem estar humano; e qual, portanto, o que está mais de acordo com a vontade divina? A teoria européia fecha os olhos ao que constitui a mais alta glória como o mais elevado dever do Estado (MANN, 1963, p. 104).

Segundo esse autor, o Estado de Massachusetts estava mais exposto devido às condições industriais e comerciais, do que outro Estado da União, aos extremos da riqueza exagerada e pobreza ilimitada, contava com uma população muito mais densa do que a média de outros Estados. E a densidade populacional é sempre uma causa que leva a desigualdade social. Mas, de acordo com a população e a extensão territorial, existia muito mais capital em Massachusetts do que em qualquer outro Estado da União norteamericana, e questionava se essas condições não seriam propícias ao risco dos males 
resultantes da concentração do capital nas mãos de uma classe e o trabalho nas mãos da outra?

A visão de Mann (1963) sobre a educação universal fazia com ele tivesse uma resposta negativa para esta questão e, conseqüentemente, uma visão altamente positiva acerca dos poderes da educação universal. Por isso, advogava a favor desta, por entender que só dessa forma romperia com o domínio do capital e servilismo do trabalho.

Constata-se que a educação universal, como defendida por Mann (1963), era a força equalizadora que agiria no interior da sociedade de Massachusetts, promovendo a igualdade entre os homens. Nesse sentido, o princípio fundamental era o da inteligência. Esta era a condição indispensável para criação da riqueza, para que existisse um povo rico e uma nação também rica.

\section{Uma proposta de modelo para a educação brasileira}

Tavares Bastos (1976), assim como Mann (1963), defendeu que a educação era um instrumento indispensável para que o Brasil atingisse o patamar das nações mais desenvolvidas. A busca do progresso e civilização transformaram-se em princípios que norteavam o caminho que levaria o país atingir o status de nação moderna.

O deputado entendia que a instrução pública seria viabilizada pela difusão de uma escola pública acessível a todos, pois tinha em vista a organização de uma escola elementar para o povo. A educação foi vista como a "mãe do progresso", ou seja a fonte geradora de transformações que propiciariam mudanças significativas na forma de pensar, sentir e agir da sociedade brasileira.

A mudança significativa seria operada, inicialmente, no interior da escola brasileira. Assim, o ensino deveria ser público, gratuito, e escola para todos. Tavares Bastos (1975) recomendava além de maior autonomia sob o ponto de vista administrativo, liberdade de ensino e condições adequadas para o funcionamento da escola pública, liberdade e igualdade no direito de culto para todos, de toda e qualquer religião. Contrário ao excesso de formalismo, cobra atenção dos administradores, a fim de que atendessem as exigências inerentes à formação pedagógica do professor, condição que ele considerava elementar para um país que sonhava atingir os parâmetros do progresso.

Adepto da formação baseada na valorização das ciências, considerava imprescindível que o professor fosse preparado adequadamente para o exercício da profissão. Sem perder de vista o modelo de escola e da educação norte-americana, Tavares Bastou (1975) pensava que um "Programa de ensino" deveria seguir determinadas características, as quais propiciariam maior qualidade na formação do aluno, aspectos que o levariam a estar mais apto a exercer as funções exigidas pelas necessidades oriundas da sociedade brasileira.

No entendimento de Tavares Bastos (1938), deveria ser realizada uma "reforma radical" na escola pública que vigorava no século XIX, de modo a propiciar o "desenvolvimento moral do povo", em cada uma das regiões do país, a exemplo do que defendia Mann (1963). Nesse sentido, a escola seria fundamental, mas era preciso fazer um ajuste no "programa de ensino público", retirando todas as disciplinas que não tivessem serventia.

Constata-se que Tavares Bastos (1938) interpretava que as mudanças operadas na escola norte-americana eram principalmente direcionadas aos princípios pedagógicos que regiam a formação do aluno e o preparavam para o exercício profissional. A crítica ao encaminhamento dado para essa questão já estava presente no primeiro panfleto elaborado 
pelo parlamentar. Entretanto, é possível ver que a questão voltou à pauta das críticas efetuadas por ele, também no panfleto que lançou em 1862, as Cartas do Solitário em que ele discute acerca da preparação do aluno e o papel atribuído aos "conhecimentos úteis".

Percebe-se que Tavares Bastos (1938) defende, na quarta carta, que fossem mantidas no novo programa de ensino as ciências que disseminassem maior racionalidade ao aluno da instrução primária, o que contrariava os defensores da formação de cunho humanitário. O parlamentar descartava do currículo escolar o latim, a retórica e a poética, disciplinas que, segundo ele, não favoreciam nenhum resultado perceptível, além de significar, para os jovens, a perda de quatro ou mais anos de uma fase tão preciosa da vida.

E, em oposição a essas disciplinas, defendia que

a instrução primária obtida nas escolas não é ainda em si mesma outra cousa mais do que um instrumento: e a que se deve logo aplicar este instrumento? À aquisição de conhecimentos úteis, às ciências positivas, à física, à química, à mecânica, às matemáticas, e depois à economia política. Estes são os alimentos substanciais do espírito do povo no grande século em que vivemos (TAVARES BASTOS, 1938, p. 65).

Verifica-se que, para Tavares Bastos (1938), o ensino das ciências deveria balizar a formação do aluno na escola brasileira, por acreditar ser capaz de preparar tecnicamente o aluno para enfrentar as exigências de uma sociedade em constante transformação, independente da região onde residisse. Convencido desse princípio, expressa na quarta carta, o entendimento que tinha sobre o que seria um "cidadão útil à pátria". Para a criança, que vivia tanto no campo quanto na cidade, deveria ser entregue "a chave da ciência e da atividade, a instrução elementar completa" (TAVARES BASTOS, 1938, p. 67) e, depois, as noções de física.

Ao discorrer acerca do programa de ensino, acrescentava, enfaticamente, que o aluno deveria ser afastado dos "mestres pedantes de latim e retórica" e, desse modo, seria preparado o jovem para ser

um cidadão útil à pátria, um industrioso, um empresário, um maquinista, como é o inglês, como é o norte-americano, como é o alemão; será um homem livre e independente, e não desprezível solicitador de empregos públicos, um vadio, um elemento de desordem (TAVARES BASTOS, 1938, p. 67).

Constata-se que a sugestão propiciada por Tavares Bastos (1938) indica a crítica feita por ele aos estudos de humanidades ${ }^{4}$, visto que visava à formação do espírito e assim tendia a desenvolver algumas qualidades no aluno a exemplo de clareza no pensamento e na expressão, o cuidado no encadeamento das idéias e das proposições, a preocupação com a medida, o equilíbrio e a adequação necessária e possível, da língua a idéia e neste sentido o jovem era preparado para o exercício de tarefas nos quadros da burocracia de Estado.

Percebe-se que, para Tavares Bastos (1938), o ensino de retórica e poética deveria ser dispensado e, se acaso os pais se interessassem em aperfeiçoar seus filhos no "gosto pela antiguidade", que o fizessem, enviando-os para as escolas particulares que mantivessem o latim nos programas de ensino, até porque considerava um erro pensar que aulas "imperfeitas e insuficientes" pudessem fornecer a alguém a aprendizagem do latim e da cultura clássica. Para ele, elas não se prestavam ao ensino da língua de Cícero e, bem menos ainda, à literatura do século de Augusto. 
Mas, a oposição do deputado ao ensino de latim ${ }^{5}$, retórica e poética justificava-se muito mais pelo fato de ele defender a formação do "cidadão útil", do que por outras razões. Por conta disso, referia-se pejorativamente às medidas adotadas pelo país a esse respeito, por constatar que, em vez de observar e obedecer às tendências do século, mantinham-se aquém do desenvolvimento, questionando: "o que possuímos nós?" (TAVARES BASTOS, 1975, p.157). E a resposta dava conta de um país que havia implantado poucas "escolas de abc", sendo que a maioria delas não possuía prédios próprios, mobília adequada e os mestres eram pouco preparados, além de serem ministradas algumas aulas de latim, "espalhadas aqui e ali" (TAVARES BASTOS, 1975, p.157).

A defesa de uma escola mais voltada para a técnica e dedicada às necessidades mais imediatas do país regia os ideais de Tavares Bastos (1938), o que justificava a valorização que ele concedia às escolas profissionalizantes. Por isso, defendia que a reforma da instrução pública deveria permitir, ao homem brasileiro, o emprego de suas energias num útil trabalho à nação.

Como o interesse de Tavares Bastos (1938) estava voltado para outra direção, ou seja, para o modelo norte-americano, defendia que era imprescindível modificar o programa de ensino, no sentido de preparar o jovem para o exercício de tarefas mais afeitas às necessidades da indústria, do comércio, enfim, que oferecessem mais aplicações práticas e úteis para o crescimento econômico e social do país, dirigindo-o, assim, para os caminhos do progresso e aproximando-o, cada vez mais, das nações civilizadas.

No que diz respeito ao interesse de Tavares Bastos por países do Velho Mundo, cabe considerar que o interesse do autor/parlamentar se voltava não para qualquer país europeu, mas para a Inglaterra, Alemanha e França. Porém, é possível perceber que outro modelo sobrepujara a Europa. O modelo de civilização e de progresso que Tavares Bastos (1938) vislumbrava era o modelo industrial, desenvolvido em toda sua potência nos Estados Unidos da América. Esse fato o levou a desenvolver uma visão mais pragmática da realidade brasileira em decorrência da pressa que tinha de ver as transformações acontecerem.

Por isso, enfatiza, na décima oitava carta, que o Brasil tinha por missão econômica a que havia sido destinada a toda a América, que entendia ser o de "celeiro da Europa", sintetizando isso na seguinte afirmação: "a missão da América estava traçada: enquanto na Europa se condensava o povo à roda das cidades, enchendo as oficinas da indústria manufatureira, aqui ele deveria espalhar-se pelos campos fertilíssimos" (TAVARES BASTOS, 1938, p. 267-268).

De acordo com o autor/parlamentar, o Brasil, além de não ter vocação manufatureira, de não ser fabricante, também não tinha "gênio marítimo". Nesse aspecto, discordava do bispo Azeredo Coutinho que, segundo Tavares Bastos (1938), "lisonjeava a vaidade nacional", discorrendo sobre uma rara aptidão marítima brasileira. Aptidão diversas vezes contestada pelo deputado.

Ao interpretar que a vocação do Brasil estaria no desenvolvimento do setor agrícola, criticava a maneira como o ensino primário era ministrado. Segundo ele, havia um "sentido antiagrícola", que o permitia compreender a necessidade de juntar noções de lavoura e horticultura, elementos de nivelamento e agrimensura, princípios de química agrícola e de história natural para os meninos e, para as meninas, deveriam ser ministradas lições de economia doméstica.

Portanto, o ensino deveria se dar de modo que habilitasse as crianças e os jovens tanto das cidades de todos os portes quanto os provenientes dos campos. Esse ensino 
deveria ter um caráter prático. Tavares Bastos (1975), assim como Mann (1963), esteve preocupado com a formação não só moral do futuro cidadão, mas também com uma formação que fornecesse respaldo para atuar no mercado de trabalho e atender os interesses exigidos pelos setores da agricultura, comércio e indústria.

Portanto, com vistas a incluir, na sociedade, os futuros cidadãos do Império, faziase necessário implantar escola moderna, que ministrasse conteúdos de interesse significativo. Não se tratava mais de ler, escrever e contar, como se realizara no ensino do Brasil colônia. O sentido agora era bem mais amplo, a idéia era que um grande esforço fosse depreendido para difundir informações como condição para compreender as estruturas lógicas elementares e mais profundas, no sentido de apreender o primado da razão. A cobrança era direcionada para a efetivação de um "programa de ensino" mais adequado às necessidades brasileiras e a preparação de uma nação a caminho da civilidade.

\section{A contribuição de Aléxis de Tocqueville para as argumentações de Tavares Bastos sobre a organização escolar e político-institucional}

A leitura de A democracia na América despertou a atenção, neste trabalho, no sentido de examinar a contribuição que esse estudo propiciou nos escritos produzidos por Tavares Bastos (1938), no que se refere à escola como um ambiente indispensável para a formação da unidade e identidade nacional e na discussão que trata da educação como uma forma de integrar o imigrante à sociedade brasileira, uma vez que os referidos temas suscitaram a atenção do pesquisador francês, no estudo que realizou sobre a sociedade norte-americana.

A obra de Tocqueville (2001), A Democracia na América, certamente, não demorou a entrar em circulação no Brasil após sua publicação, em $1835^{6}$, data do lançamento do primeiro tomo. Foi o primeiro livro publicado por Tocqueville, resultado da viagem que esse francês empreendeu, juntamente com o amigo Gustave de Beaumont, aos Estados Unidos da América.

Em maio de 1831, os dois jovens magistrados embarcaram no porto de Havre (França), incumbidos da missão, a eles confiada pelo Ministério da Justiça, de examinar as instituições penitenciárias norte-americanas. A missão foi coroada por um "relatório", remetido aos poderes públicos e publicado em seguida em dois tomos, com o título, $A$ Democracia na América. O primeiro é dedicado principalmente à descrição analítica das instituições norte-americanas, e no segundo, publicado em 1840, o autor ocupou-se de um conhecimento mais abstrato, verificando a contribuição da democracia sobre os costumes e os hábitos americanos.

Aléxis Charles-Henri-Maurice Clérel de Tocqueville nasceu em Paris, a 29 de julho de 1805, e morreu em Cannes, a 16 de abril de 1859. Por parte do pai, pertencia à pequena nobreza da Normandia, e por parte da mãe, tinha ligações próximas com os Malesherbes. Teve uma infância repleta de recordações tenebrosas dos acontecimentos dos primeiros anos da Revolução, por terem sido seus pais aprisionados e seu avô materno, o marquês de Rosambo, morto na guilhotina em defesa da liberdade, igualdade e fraternidade.

Em que pese os embaraços motivados pelas circunstâncias, Tocqueville integrou-se com a nova sociedade, inicialmente como magistrado, depois como membro do parlamento na fase da monarquia orleanista e também como Secretário de Assuntos Estrangeiros, num período pequeno, durante a Segunda República. Zevedei Barbu, na apresentação da obra $O$ Antigo Regime e a Revolução, de Aléxis de Tocqueville, afirma que o pensador francês 
era um liberal convicto, o que, no contexto de sua época, significava a favor da Restauração e contra as classes médias, tendo-se em vista os seus laboriosos esforços para atingirem uma posição de dominação política. Desapontado com a orientação política da França, particularmente durante o período da Restauração, abandonou a vida política como protesto contra o coup d'Etat de Luís Bonaparte, e com o objetivo de dedicar-se ao estudo da História (BARBU, 1982, p. 13).

Tocqueville era formado em Direito e publicou, em 1835, Ensaio sobre a pobreza e $O$ Antigo Regime e a Revolução, em 1856. Os escritos deixados pelo referido autor revelam a extensão do seu interesse na viagem que empreendeu para os Estados Unidos da América. Isso pode ser constatado no documento que enviou ao seu amigo Kergorlay, em janeiro de 1835.

Inicialmente, observa que, sendo inevitável a marcha para a igualdade, a questão primordial era saber sobre a sua compatibilidade com a liberdade. E justifica:

[...] há dez anos venho pensando uma parte das coisas que logo exporei. Fui para a América apenas para me esclarecer sobre esse ponto. $\mathrm{O}$ sistema penitenciário era um pretexto: tomei-o como um passaporte que me permitiria penetrar em todos os lugares dos Estados Unidos. Nesse país, onde encontrei mil objetos que estavam fora da minha expectativa, percebi que muitos deles diziam respeito às perguntas que tantas vezes fizera a mim mesmo (TOCQUEVILLE, 2001, p. XIII).

O autor explicita que muito mais que se informar acerca do sistema penitenciário norte-americano, seu interesse era ver, in loco, como se desenrolavam, nos Estados Unidos, os ideais de igualdade e de liberdade, como, na prática, esta questão estava sendo trabalhada pelos norte-americanos. Em Tocqueville (2001), evidencia-se também a pequena comunidade política, uma vez que nela é possível proporcionar a solidariedade tão necessária para incentivar a prática da virtude cívica e a preservação da liberdade.

Algumas destas questões foram vistas por Tavares Bastos (1975) e permitiram que ele formulasse uma compreensão acerca da realidade brasileira. $O$ entendimento do deputado alagoano revelou-se indispensável para o que ele formulou sobre o papel das províncias no âmbito da organização política, administrativa e social do Brasil do século XIX. Assim, é perceptível que a descentralização administrativa, o papel das leis para o funcionamento das instituições, e a importância dos costumes e hábitos na formação do "caráter nacional" da população, foram aspectos privilegiados por Tavares Bastos (1975).

Tavares Bastos $(1938,1975)$ não perdia de vista que o investimento em prol da vinda de imigrantes para o Brasil poderia trazer benefícios no âmbito material, mas também sob o ponto de vista cultural. Se Tocqueville (2001) analisou de forma positiva a presença do imigrante como um elemento fundamental e propiciador do amálgama cultural da sociedade norte-americana, Tavares Bastos $(1938,1975)$ compreendia que o imigrante poderia desempenhar um papel semelhante e contribuir para a regeneração moral do povo brasileiro.

È possível afirmar ainda que outros elementos identificados e analisados por Tocqueville(2001) em A Democracia na América foram incorporados às reformas advogadas por Tavares Bastos para o caso brasileiro. Um exemplo, que pode ser tomado como um referente significativo é a compreensão que o interprete da cultura e sociedade norte-americana destaca em relação à comuna, pois, ao defender a autonomia da província, o autor alagoano parece ter tomado como modelo a comuna, que era, segundo Tocqueville 
(2001, p. 70), o centro da unidade norte-americana e, entre todas as liberdades, era a da comuna a fundamental e esse era um dos motivos pelo qual Tavares Bastos (1975) envidava esforços para que as províncias passassem a ser vistas como uma espécie de comuna.

A virtude cívica seria exercitada por meio da participação nas instituições políticas locais. Nelas, o cidadão aprenderia a vantagem de ser livre e pelo próprio interesse seria fomentada a vitalidade da democracia local, como havia afirmado Tocqueville (2001). Neste sentido, a experiência e a prática da ação política propiciariam a maturação de um corpo eleitoral fundamental para o fortalecimento da democracia. Assim, a comuna seria uma espécie de escola no exercício da virtude cívica.

A aquisição da virtude cívica, por meio da experiência e do hábito da participação política, também foi vista por Tavares Bastos (1975) como um aspecto positivo que a província poderia proporcionar ao brasileiro. A formação do futuro cidadão não iria depender, somente, da instrução pública, mas também do exercício da ação política no âmbito da província. Assim, esta teria papel significativo na formação de costumes e hábitos democráticos.

Admitida a autonomia das províncias, não obstante a participação do governo central no que se refere à educação pública, a reforma da instrução, defendida por Tavares Bastos (1975), além de espalhar escolas, prescrevia que o ensino deveria ser público, obrigatório para todo o povo e pautado nos "conhecimentos úteis", ministrado por professores e era indispensável que os estabelecimentos de ensino fossem dotados não só de pessoas gabaritadas para o exercício da tarefa, mas também de meios materiais que propiciariam a realização do empreendimento.

\section{Considerações finais}

É importante destacar também que o autor/parlamentar, ao preservar esses elementos, via, no modelo de reforma implementado por Horace Mann, alguns elementos que poderiam ser adaptados à realidade brasileira e serviriam de solução para pautar o conjunto de transformações que pensava poder implementar no Brasil, pois, embora houvesse defendido a liberdade de criação da escola pela iniciativa particular, parecia plenamente convencido de que ela seria insuficiente para atender as necessidades de uma população que precisava cada vez mais de escolas, defendendo, por isso, que a participação do governo nessa área seria fundamental.

Cabe ressaltar que, mesmo advogando a favor da participação do governo para garantir a execução de um "programa de instrução pública", o autor/parlamentar estava ciente das condições econômicas e financeiras do país e, conhecedor das limitações nessa área, propunha a criação de um imposto especial - a taxa escolar, cuja finalidade seria ampliar os recursos que deveriam ser revertidos para o funcionamento da escola pública.

Destaque-se ainda que, mesmo o autor se inspirando ou tomado a reforma de Mann como referente significativo, ele procurou incorporar os elementos que achava passível de serem adequados à realidade brasileira. Esse fato acabou garantindo aspectos de singularidade ao "programa de instrução pública" idealizado por Tavares Bastos, pois, ao mesmo tempo em que propunha a criação do imposto especial, o autor/parlamentar defendia que a escola pública brasileira devesse ser laica e que as confessionais devessem ser mantidas por aqueles que as freqüentassem. Apesar de se dizer católico, não perdia a oportunidade de defender a liberdade religiosa e o casamento civil entre os não católicos. 
Diferente de Mann, Tavares Bastos não defendia os princípios da frenologia, que marcaram os estudos do reformador de Massachusetts, mas acreditava que a raça negra precisava ser reabilitada e que tanto a presença do sangue do imigrante, sobretudo norteamericano, poderia realizar, em parte, essa tarefa, quanto o acesso à escola poderia fazer surgir um homem moderno e afinado com as necessidades mais urgentes do Brasil, no século XIX, que era fomentar o progresso e a civilização.

Um fato que cabe mais uma vez ser ressaltado é, em que pese Tavares Bastos ter defendido a república norte-americana, não deixava claramente registrada a opção nesse sentido, preferindo manter a forma de governo que vigorava no Brasil, com uma recomendação expressa: era preciso conceder mais autonomia às províncias. Estas, autônomas, fariam funcionar uma estrutura em que a instrução pública seria a fomentadora do ideal de liberdade e contribuiria para que o país alcançasse o progresso.

Constata-se que Tavares Bastos compreendia que, por meio do "programa de instrução pública", poderia promover mudanças passíveis de afastar os "males "herdados, sobretudo, da colonização portuguesa, reparando-os se aplicado, adequadamente, um tipo de "remédio" que afastasse o país do atraso e ignorância, fazendo-o ingressar na "órbita dos países civilizados" e conferindo à gente brasileira maior capacidade para viver numa sociedade mais harmônica e obediente aos princípios equalizadores da democracia.

Por fim, cabe ressaltar que Tavares Bastos ao se afastar do entendimento da maioria dos seus pares parlamentares, que viam nos países europeus a solução para os males que, à época, afetavam a sociedade brasileira, acabou por pensar em um "programa de instrução pública" peculiar, ao tomar como referentes aspectos de modelos norte-americanos.

\section{Referências}

ANNUAL REPORTS. Disponíveis em

www.mass.gov/statehouse/statues/mann_report.htm e

www.tnell.com/ted/tc/12th_report.html. Coletado em 3 de julho de 2006.

BARBU, Zevedei. Apresentação. In: TOCQUEVILlE, Aléxis. O Antigo Regime e a Revolução. Brasília: Editora Universidade de Brasília. 1982.

BEREDAY. George Z. F., VOLPICELLI, Luigi. Educação pública nos Estados Unidos. São Paulo: IBRASA. 1963.

BODOLATO, Robert. The Educational Theory of Horace Mann. 2005. Disponível em http://www.newfoundations.com/GALLERY/Mann.html23. Coletado, em 27 de junho de 2006.

BUCK, Thomas M. A Leadership challenge: Horace Mann and Religion in Public Schools. Lutheran Education, vol. 138, n 2. 2002.

CHERVEL, André, COMPÈRE, Marie-Madeleine. As humanidades no ensino. Educação e pesquisa, São Paulo, nº 2, pp. 149-170. 1999.

CREMIN, Lawrence A. Prefácio. In: MANN, Horace. 1963. A educação dos homens livres. São Paulo: IBRASA.1963 a. 
O futuro da escola comum americana. In: BEREDAY. George Z. F. e VOLPICELLI, Luigi. 1963. Educação pública nos Estados Unidos. São Paulo: IBRASA. $1963 b$.

GRANT, Barry. Education without compulsion toward new visions of gifted Education. Journal for the Education of the gifted. Volume 39, $\mathrm{n}^{\circ} 2.2005$.

GROSS, Neal. In: BEREDAY. George Z. F. e VOLPICELLI, Luigi. Educação pública nos Estados Unidos. São Paulo: IBRASA. 1963.

HEELY. Allan V. 1963. A escola particular na educação americana. In: BEREDAY. George Z. F. e VOLPICELLI, Luigi. Educação pública nos Estados Unidos. São Paulo: IBRASA.1963.

MANN, Horace. A educação dos homens livres. São Paulo: IBRASA.1963

PONTES, Carlos. Tavares Bastos. São Paulo: Companhia Editora Nacional (Coleção Brasiliana). 1939.

SOUZA, Roberto Acízelo de. $O$ império da eloqüência: retórica e poética no Brasil oitocentista. Rio de Janeiro: EDUERJ/EDUFF. 1999.

SPRING, Joel. Democracy and public schooling. International. Journal Social Education. Volume 11. 1996.

TOCQUEVILlE, Aléxis de. A Democracia na América. São Paulo: Martins. 2001.

TWELFTH ANNUAL REPORT. Disponível em www. wadsworth.com/history_d/templates/student-resources/0030724791_ayers. 1848. Coletado em 30 de julho de 2006

VIEIRA, David Gueiros. O protestantismo, a maçonaria e a questão religiosa no Brasil. Brasília: Editora da Universidade de Brasília. 1980.

WARDE, Mírian Jorge. Americanismo e Educação - um ensaio no espelho In: São Paulo em perspectiva. São Paulo. V.14, Nº 02.2000. (digitado). 2001.

Americanismo e educação: a fabricação do "homem novo". São Paulo: Viagem de William James ao Brasil na expedição de Louis Agassiz: refutando a imagem do Brasil e dos brasileiros (1865-1866). XXII Simpósio Nacional de História, João Pessoa - PB. 2003.

WEILER, Kathleen. Hope and History: What do future teachers need to know?. Radical Teach, $\mathrm{n}^{\circ}$ 65. 2003. 
Obras de Tavares Bastos

TAVARES BASTOS, A. C. Cartas do Solitário. São Paulo: Companhia Editora Nacional (Coleção Brasiliana). 1938.

A Província. São Paulo: Companhia Editora Nacional (Coleção Brasiliana). 1975.

.Os males do presente e as esperanças do futuro. São Paulo: Companhia Editora Nacional (Coleção Brasiliana).1976a.

. Memórias sobre a imigração. São Paulo: Companhia Editora Nacional (Coleção Brasiliana). 1976b.

. A situação e o Partido Liberal. São Paulo: Companhia Editora Nacional (Coleção Brasiliana). 1976c.

Reforma Eleitoral e Parlamentar. São Paulo: Companhia Editora Nacional (Coleção Brasiliana).1976d.

. $O$ vale do Amazonas. Belo Horizonte: Ed. Itatiaia. 2000.

\footnotetext{
${ }^{1}$ Optou-se, neste estudo, por utilizar a expressão common school, por entender que não há, no Brasil, um termo correlato para indicar a finalidade como essa expressão foi adotada no ambiente norte-americano, principalmente na reforma empreendida por Horace Mann, ressaltando que, nos casos em que são utilizadas citações do texto de Lawrence Cremin (1963a), foi respeitada a opção do tradutor.

${ }^{2}$ Cabe justificar que devido à dificuldade de conseguir os relatórios no seu formato original, foram utilizadas algumas cópias captadas nos seguinte endereços: www.mass.gov/statehouse/statues/mann_report.htm, usinfo.state.gov/usa/infousa/facts/democrac/16.htm, www.tnell.com/ted/tc/12th report.html, www.warsworth.com/history d/templates/student-resources/0030724791-ayers, (coletada em 3 de julho de 2006) e as compilações apresentadas por Cremin (1963a), na obra denominada A educação dos homens livres [The Republic and the school - Horace Mann: on the education of free men]. A tradução do texto utilizada nesta pesquisa foi realizada por E. Jacy Monteiro e publicada em 1963.

${ }^{3}$ Horace Mann também publicou o The Common School Journal como um meio para divulgar e disseminar todos os tipos de informação sobre vários tópicos relacionados a educação (Cf. Buck, 2002).

${ }^{4}$ Acerca da exclusão da retórica e da poética, o estudo de Souza (1999) explicita que a crítica literária oitocentista, seguindo a crítica mundial, tomou o historicismo como seu modelo orientador em detrimento da vertente retórico-poética. Para esse autor, o que motivara a exclusão da retórica e da poética do plano de estudo, por exemplo, do Colégio Pedro II, havia sido a pobreza da produção didática, que não teria superado as exigências da época, ficando à mercê de "professores despidos do senso de literatura" (Souza, 1999, p. 27), ou mais explicitamente, como afirmou Antonio Cândido (apud Souza, 1999, p. 27) sobre os autores dos tratados publicados que denotavam "inconsciência total da evolução estilística e métrica (...) todos [escreviam] como se estivessem nos tempos de Felinto Elísio" . Identifica-se que a essa razão somavam-se outras: a distância estabelecida em relação à produção vitoriosa que, naquele momento, teria levado essa escola literária a sepultar a vertente retórico-poética. Esse sepultamento justificava-se pelo fato de essa vertente ser vinculada à concepção clássica de arte, a que o romantismo se opunha. Outra razão concernia ao êxito da história literária em decorrência da adesão ao projeto nacionalista (Cf. Souza, 1999).

5 Desde meados do século XVIII que, na França, tanto o programa de escolar das humanidades e, principalmente a predominância do latim, começou a ser objeto de crítica ou de condenações, que não pararam de crescer em número, intensidade e pertinência ao longo das décadas (Cf Chervel e Compère, 1997, p.27).

${ }^{6}$ Dedução construída a partir da afirmação que segue: "Seu [de Aléxis Tocqueville] primeiro livro, American Democracy (1834), foi quase espontaneamente um best-seller na Europa Ocidental" (Barbu, 1982, p.11).
}

Artigo recebido em: 19/10/2009

Aprovado para publicação em: 21/01/2010 